\title{
Integrated Sport: From Theory to Practice
}

\author{
Angela Magnanini and Pau Espinosa \\ Department of Movement, Human and Health Sciences, University of “Foro Italico", Rome 00135, Italy
}

\begin{abstract}
This paper is articulated in two parts. The first one has a theoretical approach in order to put the basis of an Integrated Sport model, built through Special Education principles. On the second part, the questionnaire which has been developed by the theoretical approach basis analysis tries to highlight Integrated Sport essence, focusing on the participants (athletes with and without disability) of the First European Day of Integrated Sport organized in Rome, from the 22nd to the 24th of May. It will look for clarify the necessity of creating the "third way of Sports" where people with and without disabilities play together in the same time and context, on the equal opportunities basis and active participation. In the research, 82 people (male $n=53$; females $n=29$ ) were selected, of which 50 did not have any kind of disability while the remaining 32 had any disability, from twelve different countries (Italy, Spain, Lithuania, Slovenia, Greece, France, Romania, Turkey, Germany, Portugal, UK and Poland), taking part in the Sport Day event as athlete, trainer, organizer, familiar or others. The medium age of participants was 31.7 years.
\end{abstract}

Key words: Integrated Sport, integration, Special Education, disability.

\section{Introduction ${ }^{1}$}

This essay tries to present a proposed model of Integrated Sport, which beyond the sport exclusively for people with disabilities (Adapted Sport). This proposal is based on the Integration principles and Education for all, developed by the Special Education.

This is why we talk about this model as one possible model and not as the model, because our work is focused on articulating a suggestion of open Sport: accessible, welcoming and linked to the discipline that toady in Italy stands as the knowledge aimed to encourage the formation of a global personality of people with Special Educational Needs (SEN), highlighting the abilities which consent a better self-expression and a better quality of life. Special Education values the whole person that, according to Pavone, actually taking a direction in order to "offer specific answers to specific problems in normal contexts and not segregated" [1]. Canevaro, one of the greatest scholars of Italian Special Education, retains

Corresponding author: Angela Magnanini, Ph.D., assistant professor, research field: special education.

${ }^{1}$ Both authors developed the text jointly, specifically: paragraphs 1, 2, 3 and 9 are written by Angela Magnanini; 5-8 by Pau Espinosa. that Special Education has the target of responding to the needs wherever they are and not to the needs grouped by categories [2]. Our starting point is the Special Education and his knowledge about inclusive education. This science can help us to change the sense of sport.

The process of integration people with disabilities (study object of the special education) in the "normal" schools distinguishes Italy from other European countries where the specificity of the historical-cultural paths, the conceptual and terminology models, the organizational and policies of lines, take the development of actions outside of the ordinary contexts [3].

The choice of integration in Italy since the Seventies of the Nineteenth century stands at the centre of the Special Education discourse ${ }^{2}$. On the one hand, the

\footnotetext{
${ }^{2}$ Integration started in 1971, when, under Law 118, compulsory education had to take place in regular classes, except in the case of mental deficiencies or physical impairments so severe as to prevent learning or integration in common classes. The same Law also places an onus on municipalities to make school buildings accessible for everyone, according to national standards; Law 517/1977 legislated to implement procedures to integrate handicapped pupils by providing special teachers, both in primary and middle schools; Law 104/1992 is the main framework for all disability issues: it guarantees specific rights for people with disabilities and their families, provides
} 
educability idea beyond each own characteristics in order to become an actor of the Educational process; on the other hand, the integration idea as a essential process to achieve a free society, open, in which the differences are resources and not insuperable obstacles [4].

Integration becomes a cultural and social changes engine, but an integration understood as Moliterni [5] claim: as process through which individualize aspects of interconnection between different subjects and situations, rebuilding a unified and deeper vision of context. Integrate in the sense of conscious reconstruction of the diversity parts. Also, integrate to get together and build together, through the inter-connection of the multiplicity, in a process that change and valorise all.

In broader terms Special Education means an Integration that is feed by contexts and integrated paths (common contexts enriching) can be understood "as a pluridirectional educational (ethical-ameliorative-growth) process of construction to achieve a complex and flexible system of relations, interactions and social, political and cultural actions capable of making all people participative, active and fully involved, without distinction of any kind, in all segments of life and at all stages of their existence, in order to give birth to an open, non-discriminatory society, where the citizens become the creators and protagonists of their own

assistance, stipulates full integration and the adoption of measures for prevention and functional recovery, and also ensures social, economic and legal protection. The principle of integration and the right of pupils with disabilities to receive specific support are also included in all the subsequent legislation that regulates general aspects of the educational system, such as enrolment, class size and pupil assessment, as well as curricular teacher training and support teacher training; Law 328/2000 states that families, together with municipalities and social services, may agree upon an individualised life project for their children, aimed at full integration 'within the family and social life'; Law 170/2010 recognises dyslexia, dysgraphia, dysorthographia and dyscalculia as specific learning disorders. This Law - which states that pupils with learning disorders do not need special teachers, but rather a new way of teaching, according to their way of learning promotes a change in perspective. The aim is to shift the focus from a clinical to a pedagogical view, by empowering all subjects involved in the educational process. destiny" [6].

In this direction, the sport that Special Education thought can only be an "integrated" sport, played in environments and common contexts with the active participation of all people involved, with and without disabilities, in a reciprocity dimension.

From our point of view, the pedagogical knowledge represents a favourable environment in order to create a model of sport for all and, thus, integrated [7], because it submit the sport under review of the usability and practicality of persons with disabilities, which puts a strain on the existing models of sport. This opens up exciting paths to reflect on the inclusive and social dimension of sport as an opportunity for growth, fun and caring to himself and to others.

The need is to overcome the limits and the barriers imposed by the medical sciences and technologies that reserve for the sport a therapeutic role or a professionalizing one of a sport that selects and chooses athletes, segregating them on sports for able-bodied people and sports for people with disabilities. Is it possible to find out a new way, the third one, without denaturalizing the sport essence, without making it became a pastime activity?

The sport for all model which will be presented here in its articulation and development, has been mature since the year 2000 thanks to the constant research work composed by didactic and investigation that has been directed within the Special Education of Integrated Sport discipline (the only one discipline in Italy with this name) in the degree course in Technics and Science of the Sport by the Foro Italico University, in Rome. This context represents the specific place where to validate the hypothesis through a concrete and constructive experimentation with a student's sample as sport players. Our model, pedagogically founded and directed follow the purpose of allow the born of the "third way" of the sport (special-pedagogical) which is mentioned before [8] to meet the society necessities which need more and more opportunities of sharing, of common languages, of integral moments where 
everyone can find himself and in which diversity becomes a constitutive characteristic and not an something to hide.

In this research we try to support the validity of the model through the analysis of an initial fact-finding on a sample of 82 people with disabilities $(n=32)$ and without disabilities $(n=50)$, from 12 different European countries, that participated in the First European Day of Integrated Sport which took place in Rome from the 22nd to the 24th of May, 2015, trying to get the motivations and intentions of people with and without disabilities which choose this sport. This will demonstrate the validity of our third way sports.

\section{Integrated Sport definition}

It is not enough to assume that changing the regulations could transform a sport for "normal" people into a friendly, open and accessible by all one, or on the other hand modifying a sport designed for people with disabilities to think that it is accessible to all. The thing to do is redefine "abimis" the sport, in order to do its own lines of Universal Design for all.

Design for all means, from the beginning, think activities that are functional and accessible to all. The United Nations Convention of the Rights of the Persons with Disabilities has between its goals the "inclusive design for all".

Our study involves the analysis of literature in Italy of three sectors: Sport [9-15]; Special Education [2, 16-19]; and of some authors who deal with Sports for people with disabilities carefully inclusion $[4,5,7$, 20-22]. The analysis allowed us to identify the constitutive principles of the areas, then weave them together, to prepare a theoretical construct of sport integrated (synthesized in Fig. 1).

We can therefore define integrated sport as a series of gymnastic, game, exercise or movement activities practised together by able-bodied people and people with disabilities (of various degrees), whether recreationally or professionally, for the purpose of competitive challenge, where each player, through relatively intense physical effort, improves their own potential, based on equal opportunities and active participation, through flexible rules that allow for individual characteristics. This definition clearly reflects the three elements of special education that ensure the inclusiveness of sport: accessibility (to places, but especially to activities), active participation and equal opportunities (ensured by the rules). The principle of active participation brings us directly to training and how it should be organised.

\section{Inclusive Coaching}

The essence of sport integrated is building/designing workouts inclusive. To play a sport together, it requires an adequate preparation that is built through moments/activities/exercises, in the field or the track, leaded to each participant and its characteristics. We have developed some "pedagogical" phases for this training, which we believe should characterise the moments of any activity considered integrated. Training in itself is already an educational challenge, because it calls for commitment to strive to achieve continuously improved results, which have consequences for the entire well-being of the individual.

Training can be divided into five phases, each comprising targeted exercises:

(1) Observation, tolerance and hospitality (building relationships); (2) Confidence; (3) Cooperating in small or large groups (including personalised exercises if necessary); (4) Playing (technical training); (5) Thinking together. In step 4, coaches can use the STEPS methods if the conditions of the athletes require special modifications. The STEPS formula provides a framework for coaches to make changes to their coaching in the areas of SPACE, TASK, EQUIPMENT, PEOPLE and SPEED [23].

Not all athletes require the same transformation activities, so special attention is required in assessing needs and skills in order to organise the most effective training plan. 


\section{INCLUSIVE SPORT INDICATORS}

Principles of sport:

1. Corporeality; 2. Play; 3. Fun; 4. Comparisoncompetition; 5 . Official, coding and commonly accepted rules; 6. Competitive spirit; 7. Professionalisation/amateurism.

\section{Principles of Special Education}

1. Person, not disability; 2. Accessibility; 3. Acceptance; 4. Inclusion; 5. Equal opportunities; 6. Active participation; 7. Cooperation; 8. Diversity as a resource.

1. The centrality of the person; 2 . The participation of people with different health conditions; 3. Educational foundations; 4 . Roles defined on the basis of skills and not disabilities, 5. Rules with possible exceptions, therefore including flexibility; 6 . Codified spaces; 7 . Competitiveness; 8. Competition; 9. Enjoyment; 10. Active participation with equal opportunities; 11 . Adaptation of equipment and materials, if necessary, but not of the objectives; 12. Amateurism and "healthy" professionalism.

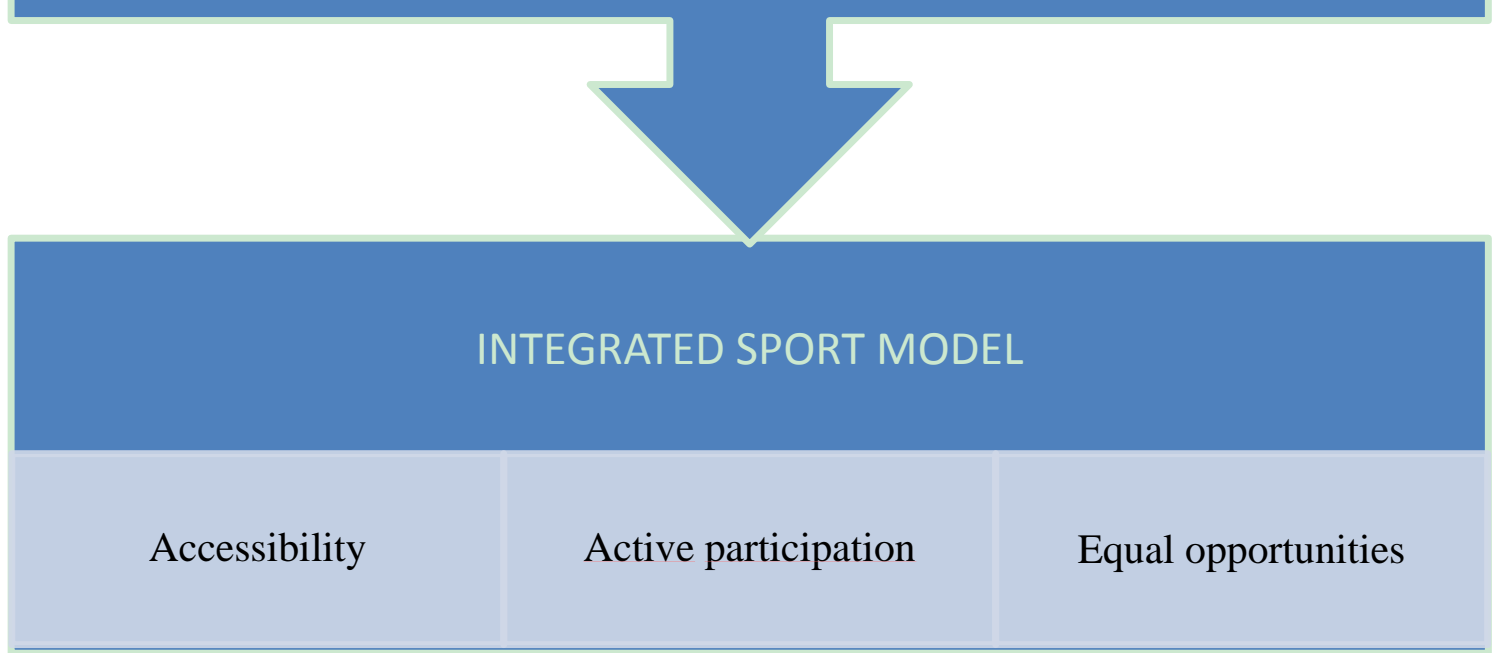

Fig. 1 Inclusive sport indicators.

The activity trainings were held together in the same space and at the same times, with the help of fellow if necessary, with moments of individual training for each respective role, in team sports, or to improve their skills.

The aim is to stimulate through sport activities the cooperation, building a mentality in which everyone take each own values and weaknesses as unique and individual, creating the bases for this mode of thought, in all areas of life.

Specifically, designing these activities is useful to focus on those phases that characterize integrated sport (Fig. 2):

(1) Observation, tolerance and hospitality (playing and being together should help to know each other. This step is necessary to propose the following activities, which are specially designed for that group of people, with those specific features). 


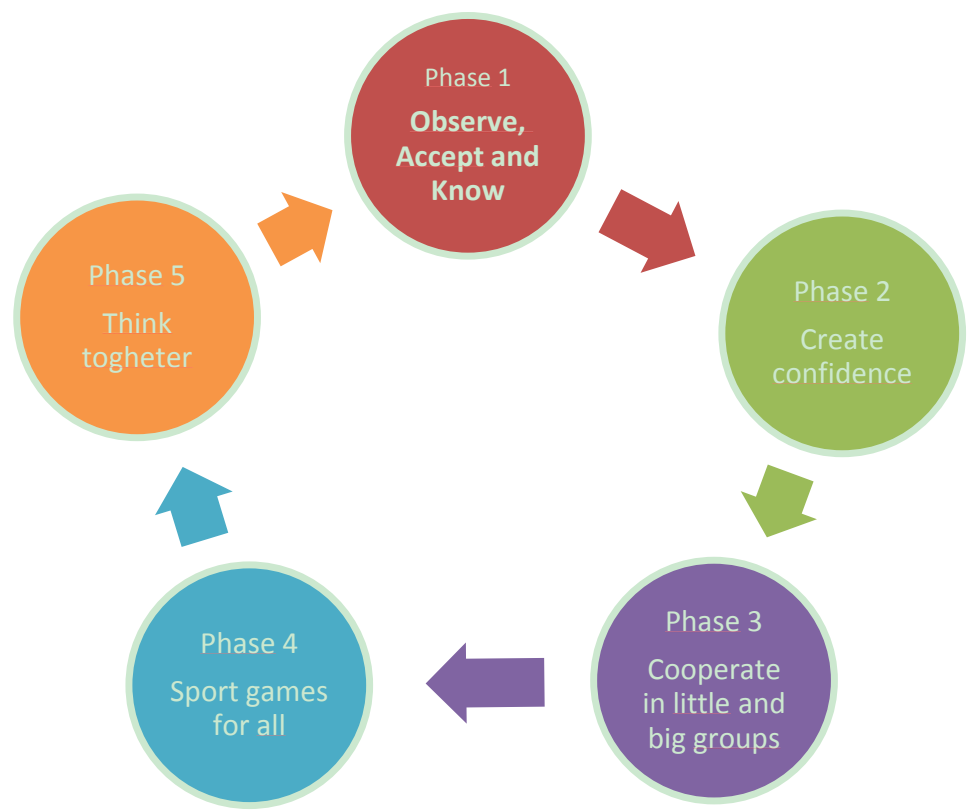

Fig. 2 Phases to build Integrated Sport activities: Everyone can play.

The first element to be transferred from the pedagogical to the sport field is the establishment of significant relationships. Observing (freely and through organized grids), knowing, understanding, reading and listening to the needs of the other play a role of essential elements of a conscious behaviour aimed at building an effective relationship, which should - from a helping relationship - be turned at first into a support and then an accompanying relationship towards the possible autonomy. The real educational relationship is the one that intentionally and strategically transfers tools that are suitable to change people and urge them to "do" by themselves. On the contrary, a relationship that does not generate autonomy processes cannot be called educational. This does not imply not helping the other, but rather through strategies, even meta-cognitive-inciting him to take possession of the elements that are significant for him in order that he can act intentionally and unleash his creative potential.

(2) Confidence (activities that are capable of creating ties of confidence).

The development of confidence, closely linked to the construction of the relationship, is an essential element in creating the conditions for people to get involved with others.

The activities focused on the development of self-confidence and integrated into an organic planning, lead people-both with and without disabilities - to be determined and resolute in providing objectives, rules and deadlines.

(3) Cooperation (activities that consolidate the relations and the spirit of cooperation and positive interdependence). In this direction, the work by Johnson and Johnson [24] on the cooperative management of a class is actually resumed. Elisabeth Cohen invites everyone to reflect with her work on the fact that you learn many more ideas and concepts by talking, meeting and discussing than with a traditional teacher-led lecture [25].

Once he has been assigned a goal, the student must get used to promote cohesion through mutual knowledge, development of group identity, promotion of mutual support and enhancement of differences. This element only works if you have reached the other phases [16].

The function of round robin becomes crucial when it comes to ensuring that a role is assigned and shared in rotation, while telling oneself. Everyone should be guaranteed full participation with the creation of a 
context of mutual interdependence [26].

This moment is important because it lays the foundation for co-planning, which will underlie the creation of an inclusive motor and sports activity, along with the maturation of a sense of individual and group responsibility.

The next step involves putting together all the elements previously tried to play together. People invent an activity designed for all, according to the characteristics of the people involved.

(4) Playing together (Technical training). Motor and sports activity suited to the group, designed on the basis of equal opportunities and equality and active participation.

(5) Reflection. At the end of the activities, it is useful to highlight how you feel and what can be improved with the contribution of all.

Each of these phases is helped by teacher examples (modeling) which invites people to reflect on the elements and to make proposals practical examples, able to build through those keywords a lesson that is accessible, inclusive, suitable for everyone and participatory.

Internationally, Great Britain has been most active in this field, together with scholars from Australia and Ireland, seeking to develop sporting practices for people with disabilities, with significant consequences for the training system in terms of full participation by the athletes.

In Italy, on the basis above analyzed in 2003 arise the Baskin (Integrated Basketball), which combines the principles of sport (basketball) and the principles of Integration, through the invention of 10 rules that follow the principles of equality, responsibility, accessibility [7]. Baskin shows that choose and practice a sport together is possible.

\section{Research Sample}

Through the second part of this paper, focusing the research through the basis of the approach explained above, it is going to study the practice of Integrated
Sport that offer a real opportunity to people with and without disabilities to do some exercise together.

A great recognition by the European Union arrived to Italy and to the CSEN (National Educational Sports Centre) in order to seal the support of the Integrated Sports. With this important decision, the European Union promotes Integrated Sport as an element of social inclusion of people with disabilities and stimulates an Integration Education path through sport practices.

After two years of National editions event dedicated to the Sports Integrated Festival, during the third it has become from a national event to a large European event with the participation of more than 16 organizations from 12 different countries, from Portugal to Romania and from the U.K. to Turkey.

The European Day of Integrated Sport took place simultaneously in 132 Italian cities, providing 12 integrated disciplines, involving 5340 athletes with and without disabilities. Eight of these disciplines are individual such as wheelchair fencing, dancing, horseback riding, table tennis, judo, archery and dog agilities and four group sports: football 5, integrated football, basketball and integrated basketball.

The aim of our research, which is connected with the theoretical reflections exposed before, is to figure out who is the person that chooses Integrated Sport built and the choice reason.

The results that we expect should support, or not, the vocation of the Integrated Sport: to be a sport in every way, with an inclusive behaviour, and then not a just a hobby or a rehabilitation sport activity.

These collected data, take part from the first research sample that will be collocated with future research data of the Integrated Sports events hold in Italy during the 2015. Data are only descriptive, but this data are an important starting point in a Sport industry that is doing the first moves in the complex mosaic of pedagogical research in the Sport field.

\section{Methodology}

The study was developed in two parts: the first one 
during the Sport activity day through interviews to people that freely wanted to participate in the research. In order to increase the sample of the research, secondly, we decided to send the questionnaire by mail to all participants. All information is held confidential to be coded and analysed.

The research was carried out through questionnaires with 11 closed questions, based on previous academic research [27-30].

The first 6 questions were to know the main characteristics of respondents while the remaining 5 questions were to know more about the motivation that has led each one to participate in the European Day of Integrated Sports. During the creation of the questionnaire was considered important to make questions as simple as possible to ensure that people with cognitive disabilities could understand it. By the same token, it is important to note that people with severe disabilities were helped by technical staff or familiars to answer questions.

\section{Data Analysis}

Through the first questionnaire questions, we wanted to get information about participants of the Sport event. The aim of this research part was to know the characteristics of people who participate, it means, if they have any disability and its nature, the gender, age and the role that plays during the day Integrated sports.

Questionnaires data were coded in the SPSS program to make a quantitative analysis. Through this analysis were carried out calculations relating to the frequencies, means, standard deviations and correlation coefficients.

In order to know the Integrated Sport main motivations we did a factor analysis; variance analysis (one way ANOVA); t-test to calculate significant differences between motivations of people with disabilities and people without disabilities, as well as to calculate significant gender differences; post-hoc analysis to analyse significant differences between the motivations and the different types of disabilities, as well as to calculate significant differences of countries motivations.

\section{Descriptive Analysis}

A total of 82 people participated in the research (male $n=53$; 64\%; females $n=29 ; 35.4 \%$ ). Of this sample 9 people $(11 \%$; males $n=5$; females $n=4)$ are from Spain, 8 people from Italy $(9.8 \%$; males $n=4$; females $n=4), 12$ people from Lithuania $(16.6 \%$; males $n=7$, females $n=5$ ), one person from Slovenia (1.2\%; males $n=1), 11$ people from Greece $(13.4 \%$; males $n=7$, females $n=4), 2$ people from France (2.4\%; males $n=2)$, 14 people from Romania (17.1\%; males $n=9$; females $n=5$ ), one person from Turkey (1.2\%; males $n=1), 3$ people from Germany (3.7\%; males $n=2$, females $n=1$ ), 8 persons from Portugal (9.8\%; males $n=6$, females $n=2$ ), 9 people from the United Kingdom ( $11 \%$; males $n=7$, females $n=2$ ) and four people from Poland (2.8\%; males $n=2$, females $n$ $=2$ ), where the youngest person was 15 and the oldest 68 years. The average age of participants was 31.7 years with a standard deviation score of 12.3. We decided to work with the whole sample, thought the deviation score was high, because the goal that we were going to analyse was Integrated Sport that means wide years range between participants, different abilities, at least, different characteristics between participants together.

Table 1 presents the average age by gender and by role. In Table 2, we can find the average age by country.

Of all the research participants, $50(61 \%)$ did not have any kind of disability while the remaining 32 (39\%) had any disability. Of these, 23 (71.9\%) had a physical disability, 8 (9.8\%) cognitive and $1(3.1 \%)$ sensorial.

Table 3 shows some sample information about the number of people with and without disabilities, the country of origin and the gender.

About the role that people held during European Day of Sports, we can say that 48 (58.5\%; males $n=28$; 
Table 1 Medium age by gender and role.

\begin{tabular}{lll}
\hline & & Age \\
\hline \multirow{2}{*}{ Gender } & Male & 33 \\
& Female & 29 \\
\hline \multirow{4}{*}{ What is your role } & Athlete & 30 \\
& Trainer & 33 \\
& Organizer & 34 \\
& Family & 38 \\
& Other & 28 \\
\hline
\end{tabular}

Table 2 Medium age by country.

\begin{tabular}{ll}
\hline Country & Age \\
\hline Spain & 28 \\
Italy & 38 \\
Lithuania & 29 \\
Slovenia & 28 \\
Greece & 30 \\
France & 27 \\
Romania & 29 \\
Turkey & 37 \\
Germany & 38 \\
Portugal & 35 \\
UK & 39 \\
Poland & 22 \\
\hline
\end{tabular}

Table 3 Gender, disability and country of participants.

\begin{tabular}{lllll}
\hline \multirow{2}{*}{ Country } & \multicolumn{4}{c}{ Gender } \\
\cline { 2 - 5 } & \multicolumn{3}{c}{ Male disability } & \multicolumn{2}{c}{ Female disability } \\
\cline { 2 - 5 } Ses & No & Yes & No \\
Italy & 3 & 2 & 2 & 2 \\
Lithuania & 3 & 2 & 2 & 2 \\
Slovenia & 1 & 4 & 5 & 0 \\
Greece & 7 & 0 & 0 & 0 \\
France & 0 & 0 & 1 & 3 \\
Romania & 5 & 4 & 0 & 0 \\
Turkey & 1 & 0 & 3 & 2 \\
Germany & 2 & 0 & 1 & 0 \\
Portugal & 5 & 1 & 1 & 0 \\
UK & 6 & 1 & 0 & 2 \\
Poland & 0 & 2 & 0 & 2 \\
\hline
\end{tabular}

females $n=20$ ) people have participated as athletes, 9 (11\%; males $n=7$; females $n=2$ ) as coaches, 14 (17.1\%; males $n=9$; females $n=5$ ) as organizers, 8 (9.8\%; males $n=6$; females $n=2$ ) were family and 3 (3.7\%; males $n=3$ ) support other roles.

In relation to the roles that cover, disability and we can say that:
(1) Among the athletes, 20 (41.6\%) did not have any disability while the $28(58.4 \%)$ remaining athletes had any disability. In Fig. 1, we can see the different disabilities that athletes had. Further information about athletes' disabilities are presented in Fig. 3.

(2) About the coaches we may say that $8(88.8 \%)$ had no disability and that $1(11.2 \%)$ had a physical disability.

(3) The organizers, 12 (85.7) of them did not have any disability while $2(14.3 \%)$ had a physical disability.

(4) In the family group $(n=8)$, nobody had any disability.

(5) Among those who did other, 2 (66.7\%) had no disability and $1(33.3 \%)$ had a physical disability.

In order to deepen in the descriptive analysis, we report in Table 4 the data concerning the role and the country of origin.

\section{Participants' Motivations}

This part of the questionnaire pretends to shed some light about the reasons that took the people to participate in the European Day of Integrated Sports, giving some reasons about the Sport event participation. These reasons, such as "join a relative/friend", were assessed with the 5-point Likert scale where 1 meant totally disagree and 5 totally agree. In order to analyse the results, we took the score 1 and 2 as disagree, 3 as neutral and scores 4 and 5 as totally agree.

The part of the questionnaire which let us to know the motivations of participants had 5 questions which were done as simply as possible in order to make them understandable to the people with disabilities, and in this way got the most real data possible. The participants applied the questionnaire during the Sport event, through an interview [31] and through the Internet.

In order to know the main participants motivations to the European Day of Integrated Sports, we did a factorial analysis. The main factors have been chosen through the Barlet test, choosing the factors that have an eigenvalue higher than 1 (Table 5). 


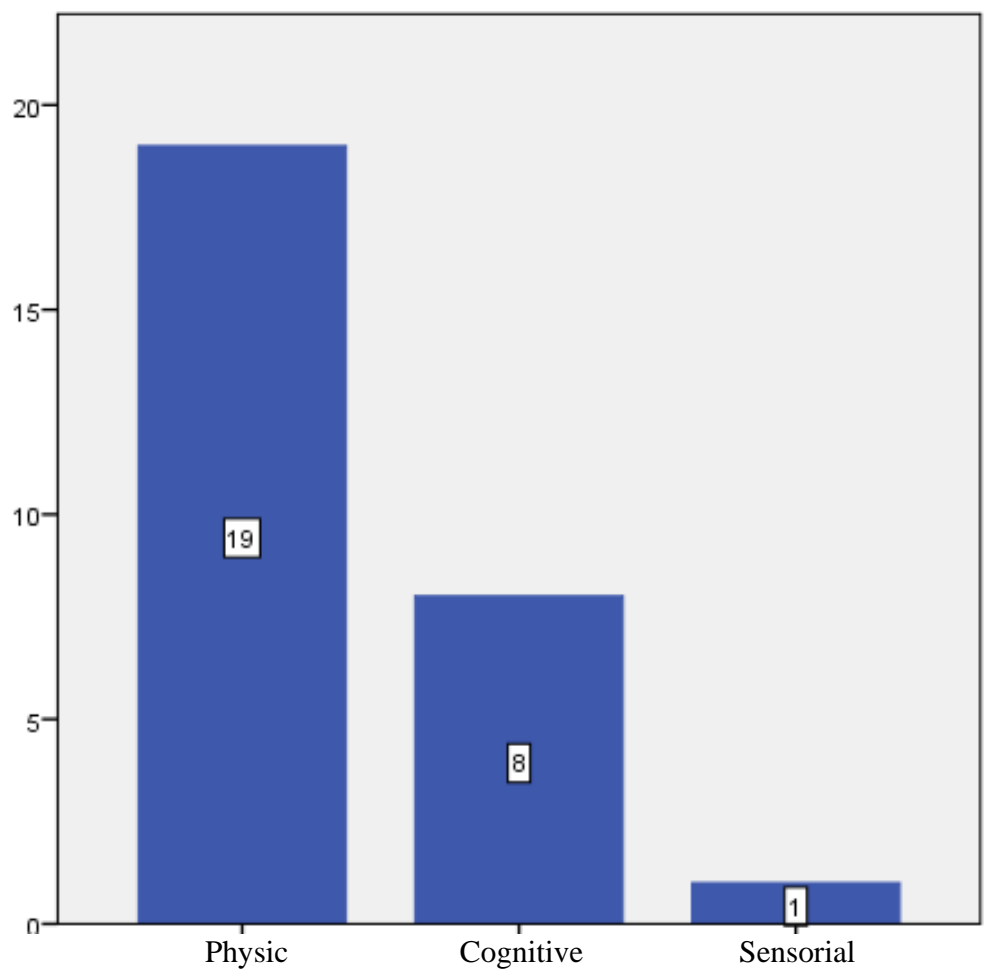

Fig. 3 Athletes types of disability.

Table 4 Roles by countries.

\begin{tabular}{llllll}
\hline \multirow{2}{*}{ Country } & \multicolumn{5}{c}{ What is your role? } \\
\cline { 2 - 6 } & Athlete & Trainer & Organizer & Family & Other \\
\hline Spain & 5 & 1 & 2 & 0 & 1 \\
Italy & 5 & 2 & 0 & 1 & 0 \\
Lithuania & 9 & 1 & 1 & 0 & 1 \\
Slovenia & 1 & 0 & 0 & 0 & 0 \\
Greece & 7 & 1 & 2 & 1 & 0 \\
France & 2 & 0 & 0 & 0 & 0 \\
Romania & 8 & 2 & 2 & 1 & 1 \\
Turkey & 0 & 0 & 1 & 0 & 0 \\
Germany & 1 & 0 & 2 & 0 & 0 \\
Portugal & 3 & 0 & 1 & 4 & 0 \\
UK & 4 & 2 & 2 & 1 & 0 \\
Poland & 3 & 0 & 1 & 0 & 0 \\
\hline
\end{tabular}

Table 5 Main participants' motivations.

\begin{tabular}{lll}
\hline Main factors & Variables & Value \\
\hline \multirow{3}{*}{ Sport motivations } & Practice Motor Act. & 0.75 \\
& Competition & 0.69 \\
& Stay with others & 0.84 \\
& TOTAL Autovalue & 2.0 \\
\hline \multirow{3}{*}{ Social motivations } & Join relative/friend & 0.57 \\
& Forced to participate & 0.71 \\
& TOTAL Autovalue & 1.2 \\
\hline
\end{tabular}

Two main factors have emerged in the search, which define the motivation for participation in the European day of sport. These motivation factors are internal motivations of game (40.4\%) and external motivation to the game $(24.1 \%)$. Both factors explained a variance of $64.5 \%$.

The results show that from the two main factors emerged in the analysis, the most important is the Sport motivation $(X=4.3)$ while social motivation stay in a second plane $(X=3.7)$.

After that, we wanted to know if there were significant differences between the countries and the two main factors that have emerged in the factorial analysis. It has made the one-way ANOVA analysis which revealed significant differences between Sport motivation and different countries $(\mathrm{F}=2.264, \mathrm{df}=11$, $P<0.05)$. In order to know between which countries there was a significant difference, it was performed a post hoc analysis using the Scheffé test. The test found significant differences between Greece $(\mathrm{X}=3.58)$ and Italy $(X=4.71)$ and between Greece $(X=3.58)$ and Lithuania $(X=4.58)$ in Sport motivations. Further 
Table 6 Sport motivation by countries.

\begin{tabular}{ll}
\hline Country & Medium \\
\hline Spain & 4.30 \\
Italy & 4.71 \\
Lithuania & 4.58 \\
Slovenia & 4.00 \\
Greece & 3.58 \\
France & 4.17 \\
Romania & 4.29 \\
Turkey & 5.00 \\
Germany & 4.22 \\
Portugal & 4.25 \\
UK & 4.41 \\
Poland & 4.08
\end{tabular}

Table 7 Main motivations by gender.

\begin{tabular}{llll}
\hline Main factors & $\begin{array}{l}\text { Male } \\
\text { participants }\end{array}$ & $\begin{array}{l}\text { Female } \\
\text { participants }\end{array}$ & Total \\
\hline Sport motivations & $\mathrm{X}=4.33$ & $\mathrm{X}=4.18$ & $\mathrm{X}=4.27$ \\
Social motivations & $\mathrm{X}=3.82$ & $\mathrm{X}=3.72$ & $\mathrm{X}=3.78$ \\
\hline
\end{tabular}

Table 8 Main motivations by people with or without disabilities.

\begin{tabular}{|c|c|c|c|}
\hline Main factors & $\begin{array}{l}\text { People with } \\
\text { disabilities }\end{array}$ & $\begin{array}{l}\text { People without } \\
\text { disabilities }\end{array}$ & Total \\
\hline Sport motivations & $X=4.36$ & $X=4.22$ & $X=4.27$ \\
\hline Social motivations & $X=3.60$ & $X=3.90$ & $X=3.78$ \\
\hline
\end{tabular}

information is explained in Table 6 .

The same analysis for different types of disability and sport and social motivations did not present significant differences.

In order to know if there were significant differences between genders and the two main factors emerged in the research, sport and social motivations, the T-test analysis determined that there were no significant differences between both groups. As we can see in Table 7, the medium between genders and motivations is very similar.

Further T-test analysis found significant differences between the groups, "people with disabilities" and "persons without disabilities" linked to the social motivation ( $\mathrm{F}=4.359, \mathrm{df}=1, P<0.05)$, and as we can see from the medium in Table 8 , people without disabilities shown on average more desire to take part motivated by social reasons.

\section{Conclusions}

Integrated sport build a whole group and unique-person that through sport practice is able to develop and promote the culture of Integration and solidarity with the acceptance and appreciation of the diversity at all levels.

All this take place in tune with the guidelines laid down by the reform of the Italian social health service (L.328/2000), which understand in an innovative way the welfare and the care and integration sense. In this way, the law promotes the participation and contribution of everyone with actions aimed to meet common needs and shared by disabled and non-disabled people. Daily experience has shown that it is more effective to develop the own autonomy integrated actions, that bring together people with different characteristics and capabilities in the same activities.

The first European day of Integrated Sport is evidence that shows how important it is to promote Integrated Sports as the third way of Sport, where normal Sport Olympics is considered as the first way and Adapted Sport Paralympics as the second way of Sport. Integrated Sport now can be considered as an additional opportunity for all to practice sports, revealed by the large number of people who participated in the event organized by CSEN and financed by the European Union. We also should mention the different activities organized for years, such as the Festival of Integrated Sport, which has leaded this form of cultural interaction and exchange between people that has different kind of abilities, but plenty of competition and participation desires. Baskin Championships (Integrated Basketball) held since 2003 in many Italian regions, testify it [7].

This Integrated Sports phenomenon is evident not only as a cultural movement but as a real needs of the whole society. It is firmly rooted in "common life verb", without denying space to Olympic and Paralympics events. At the same time, we should think to promote, 
encourage and disseminate this third way of sport, which is linked to the UN Convention of the Rights of Persons with Disabilities "Universal Design" [32]: "Universal design means the design of products, environments, programmes and services to be usable by all people, to the greatest extent possible, without the need for adaptation or specialized design."

From the heterogeneity of the sample exposed above, it is possible to see evidence in term of participation of people with and without disabilities, and different types of disabilities, through which is possible to confirm that Integrated Sport involves everyone. In fact, we can say that of 82 participants in the survey, only 32 people had any disability: 8 had a cognitive disability and 1 person a sensorial disability. In contrast, 23 had a physical disability. It make us to think that Integrated Sport must go in a more accessible path for people with sensorial and cognitive disabilities, otherwise, the Integration goal could be tainted by being a sport mainly for people with physical disabilities.

Concerning the roles, we can say that people with disabilities has little presence in coaches and organizers roles. In fact, only one person with physical disabilities participated as a coach and two also with physical disabilities, as organizers. It should make us think about the structure of sport we want. Integrated Sport should not be only a sport activity but also an occasion to people with disabilities to be integrated in a society where to face up new challenges. Furthermore, the same Integrated Sport structure should find the way to include in its organisation people with disabilities which lead with their ideas a sport open to everyone.

Regarding the Sport motivations, the factorial analysis has revealed two main factors that we have classified as Sport motivation (competition, desire to play, be with other people) and social motivation (joining a relative/friend, forced participation). The ANOVA analysis of the two main factors that have emerged and the post hoc analysis found significant differences between different countries, Greece and Italy; Greece and Lithuania, in the Sport motivation factor. Future research should be directed in order to know why there are such significant Integrated Sport motivation differences between these countries.

About people with and without disabilities, we can say that there are significant differences between both groups and social motivations. People without disabilities, in social motivation factor, have higher average score than people with disabilities, which could explain that people without disabilities practice Integrated Sports just to "assist" people with disabilities. Furthermore, it contrast with the study's results of Brasile, et al. [27] and White, et al. [29], which found that people with disabilities have more social motivations because they want to develop the own identity. In despite of this, as Weiss, et al. [33], taking part in a group is important for people with disabilities in order to be motivated for the Sport practice.

The non-statistical significance between disabilities and non-disabilities groups in sport motivations, in this case, for us is very significant. It shows that people with disabilities and people without disabilities, have chosen to participate in the European Day of Integrated Sports moved by the same kind of Sport motivations. Besides, research data in Sport motivations also shows that people with disabilities $(X=4.36)$ have a higher score average than people without disabilities $(\mathrm{X}=$ 4.22), which could explain that athletes with disabilities accept the challenge to compete with people without disabilities. This is in the same direction as Caus [34], who found that people with disabilities have more ego Sport orientation than people without disabilities.

Contrarily, if we talk about social motivation, people without disabilities demonstrate more, on average, desires $(X=3.90)$ in comparison with people with disabilities $(X=3.60)$. The higher average score let us think that possibly people with disabilities participate in this Sport because they want to be away from the 
family and meet new people [35].

From our point of view, future Integrated Sport research should be focused in the structure, regulations, and agility of the game, in order to verify if Integrated Sport is effectively a way that offers accessibility, active participation and equal opportunities for all.

\section{References}

[1] Pavone, M. 2015. L'inclusione Educativa. Milano: Mondadori. (in Italian)

[2] Canevaro, A. 1999. Pedagogia Speciale: la Riduzione dell'handicap. Milano: Mondadori. (in Italian)

[3] Canevaro, A., and Chieregatti, A. 1999. La Relazione di Aiuto. L'incontro con l'altro nelle Professioni Educative. Roma: Carocci. (in Italian)

[4] de Anna, L. 2009. Processi Formativi e Percorsi di Integrazione nelle Scienze Motorie. Ricerca, Teorie e Prassi. Milano Franco: Angeli. (in Italian)

[5] Moliterni, P. 2013. Didattica e Scienze Motorie. Tra Mediatori e Integrazione. Roma: Armando. (in Italian)

[6] Magnanini, A., and Espinosa, P. 2015. "Sport for All: Italian Model.'International Journal of Science Culture and Sport 3 (2): 113-27.

[7] Magnanini, A. 2010. Uno Sport per Tutti: Fondamenti Teorici, in Bodini, A. Capellini, F. Magnanini, A. Baskin...uno Sport per Tutti. FondamentiTeorici $e$ Progettual. Milano: Franco Angeli. (in Italian)

[8] Magnanini, A. 2011. "Una Terza Via per lo Sport. Lo Sport Integrato.” Ricerche Pedagogiche 45 (180): 27-32. (in Italian)

[9] Huizinga, J. 1938. Homo Ludens. A Study of the Play Element in Culture. Boston: Beacon Press.

[10] Caillois, R. 1981. I Giochi e gli Uomini. La Maschera e la Vertigine. Milano: Bompiani. (in Italian)

[11] Guttmann, A. 1978.From Ritual to Record.New York:ColumbiaUniversity Press.

[12] Bourdieu, P. 1979. La Distinction. Critique Social du Jugement. Paris: Éditionsde Minuit. (in French)

[13] Parlebas, P. 1997. Giochi e Sport. Corpo, Comunicazione e Creatività. Torino: Edizioni il capitello. (in Italian)

[14] Arnold, P.J. 2002. Educazione Motoria, Sport e Curricolo. Milano: Guerini. (in Italian)

[15] Gori, M. 2011. Cinesica. Roma: Aracne. (in Italian)

[16] de Anna, L. 2014. Pedagogia Speciale. Integrazione ed Inclusione. Roma: Carocci. (in Italian)

[17] d'Alonzo, L. 2006. Pedagogia Speciale per Preparare alla Vita. Brescia: La scuola. (in Italian)

[18] Pavone, M. 2010. Dall'esclusione all'inclusione. Lo Sguardo della Pedagogia Speciale. Milano: Mondadori. (in Italian)
[19] Gaspari, P. 2013. Pedagogia Speciale. Questioni Epistemologiche. Roma: Anicia. (in Italian)

[20] Sibilio, M. 2005. Lo Sport come Percorso Educativo. Attività sportive e Forme Intellettive. Roma: Guida. (in Italian)

[21] Mura, A. Ed. 2011. "L'attività Motoria e Sportiva Integrata tra Scuola ed Extrascuola. Considerazioni Teoriche e Percorsi Metodologici dalla Scuola Primaria all'Università." L'integrazione Scolastica e Sociale" 10 (4): 323-30. (in Italian)

[22] Bortolotti, A., and Farne, A. 2011. "Sportivi si Cresce. Gioco e Sport nel Contesto Formativo." RassegnaBibliografica. Infanzia e Adolescenza 11(1): 5-30. (in Italian)

[23] Black, K., and Stevenson, P. 2011. "The Inclusion Spectrum." Accessed December 19, 2015. www.theinclusionclub.com

[24] Johnson, D. W., and Johnson, R. 1989. Cooperation and Competition: Theory and Research. Edina: Interaction Book Company.

[25] Cohen, E. G. 1999. Organizzare i Gruppi Cooperativi. Ruoli, Funzioni, Attività. Erickson: Trento. (in Italian)

[26] Cacciamani, S. 2008. Imparare Cooperando. Dal Cooperative Learning alle Comunità di Ricerca.Carocci: Milano. (in Italian)

[27] Brasile, F. M., Kleiber, D. A., and Harnisch, D. 1991. "Analysis of Participation Incentives among Ahletes with and without Disabilities." Therapeutic Recreation Journal 25 (1): 18-33.

[28] Pelletier, L. G., Fortier, M. S., Vallerand, R. J., Tuson, K. M., Briere, N. M., and Blais, M. R. 1995. "Toward a New Measure of Intrinsic Motivation, Extrinsic Motivation, and Motivation in Sports: The Sport Motivation Scale SMS.' Journal of sport and Exercise Psychology 17 (1): 35-53.

[29] White, S. A., and Duda, J. L. 1993. "Dimensions of Goals and Beliefs among Adolescent Athletes with Physical Disabilities." Adapted Physical Activity Quarterly 10 (2): 125-36.

[30] Gutiérrez Sanmartín, M., and Caus i Pertegáz, N. 2006. "Análisis de los Motivos para la Participación en Actividades Físicas de Personas con y sin Discapacidad." Revista Internacional de Ciencias del Deporte 2 (2): 49-64. (in Spanish)

[31] Bramely, J., Van Kraayennoord, and C., Elkins, J. 1990. Understanding Young Women with Disabilities. St. Lucia: Fred and Eleanor Schonell Education Research Centre.

[32] United Nations. 2006. Convention on the Rights of Persons with Disabilities, New York.

[33] Weiss, C., and Jamieson, N. 1988. "Hidden Disabilities: A new Enterprise for Therapeutic Recreation." Therapeutic Recreation Journal 22 (4): 9-17.

[34] Caus, N. 2000. “Análisis de las Motivaciones hacia la 
Práctica Deportiva de las Personas con y sin Discapacidad." $\mathrm{Ph} . \mathrm{D}$. thesis, Universitat de València. (in Spanish)

[35] Lord, E., and Patterson, I. 2008. "The Benefits of
Physically Active Leisure for People with Disabilities: An Australian Perspective." Annals of Leisure Research 11 (1): 123-44. 